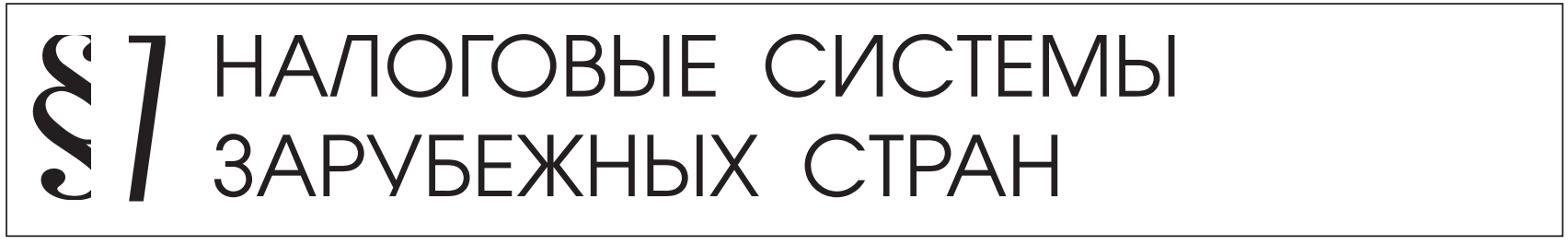

С.И. Сиражудинова

\title{
ИНФОРМАЦИОННАЯ ПОМОЩЬ НАЛОГОПЛАТЕЛЬЩИКУ КАК СПОСОБ ПОДДЕРЖАНИЯ НАЛОГОВОЙ ДИСЦИПЛИНЫ
}

Аннотация: Основная цель работы состоит в исследовании влияния оказания информационных услуг налоговыми органами налогоплательщикам на соблюдение налоговой дисииплины. В статье предоставлено исследование, отражающее эффективность сервисных программ для налогоплательщиков в цчелях поощрения подачи деклараций налогоплательщиками и увеличения уровня декларируемого дохода. На основе изложенного в статье материала автор приходит к выводу о том, что неопределенность налогового обязательства снижает подачу налоговых декларащий налогоплательщиками. Кроме того, информаџия, предоставленная налоговым органом, имеет положительное и значительное влияние на тенденцию налогоплательщика к подаче декларащии и последующее предоставление отчетности о доходах. Уровень декларирования доходов увеличивается, когда налоговый орган обеспечивает доступной информацией налогоплательщиков. В заключение обосновывается необходимость компромисса между попьткой принуждения и оказанием информационной помощи, а также расширения информационных услуг и разъяснительных работ в целях совершенствования налогового администрирования $и$ повышения соблюдения налоговой дисциплины налогоплательщиками.

Ключевые слова: Налоги и налогообложение, дисциплина, налогоплательщик, взаимодействие, услуги, информация, разъяснение, уклонение, уплата, налоговые органы

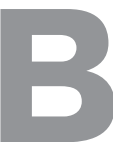

традиционной «принудительной» концепции, которая часто используется для анализа поведения, связанного с выполнением налоговых требований, налогоплательщики рассматриваются как потенциальные преступники и акцент делается на подавлении незаконного поведения с помощью частых проверок и жестких наказаний. Совсем недавно многие пришли к пониманию того, что эта концепция является неполной. Так, некоторые страны делают упор на развитие режимов «дружественного диалога» и оказания всесторонней помощи налогоплательщикам. Расширенная «сервисная» концепция усиливает роль налогового ведомства как вспомогательного звена по оказанию услуг налогоплательщикам. В действительности, многие недавние реформы налогового администрирования по всему миру включили в себя эту новую сервисную концепцию, как правило, со значительным положительным эффектом на восприятие гражданами налогового администрирования. Модернизация налогового администрирования в развитых странах все более осуществляется в интересах налогоплательщиков и для налогоплательщиков. Например, в США взаимодействие между налогоплательщиками и налоговым управлением (IRS является подразделением государственного казначейства США) осуществляется, прежде всего, на основе информационных писем. Во Франции отношения между налоговым орга- 
ном - главным налоговым управлением и налогоплательщиком строятся в форме обмена мнениями: каждая сторона отстаивает свою правоту. Налоговая администрация обязана только в письменном виде отвечать на вопросы налогоплательщика. Последний может использовать эти ответы для отстаивания своих интересов. Налоговые декларации по итогам отчетных и налоговых периодов чаще всего составляются аудиторскими и налоговыми консультациями, нередки случаи предоставления части указанных услуг на безвозмездной основе. Санкции зависят от того, были ли действия плательщика умышленными, а также помогает ли налогоплательщик налоговым органам. В случае простых ошибок применяются более мягкие наказания. ${ }^{1}$

Тем не менее, в то время как подобные «более дружественные» установки могут улучшить имидж налогового органа, их фактическое влияние на соблюдение налогоплательщиками налогового законодательства, не было, насколько нам известно, систематически изучено. В этой работе мы используем эксперименты, чтобы проверить эффективность сервисных программ для налогоплательщиков как для поощрения подачи деклараций налогоплательщиками, так и для увеличения уровня декларируемого дохода. Наши результаты показывают, что неопределенность снижает подачу налоговых деклараций налогоплательщиками. Мы также считаем, что информация, предоставленная налоговым органом, имеет положительное и значительное влияние на тенденцию налогоплательщика к подаче декларации и последующее предоставление отчетности о доходах.

Мы предлагаем несколько преимуществ эмпирических исследований на базе реальных

\footnotetext{
${ }^{1}$ Актуальные проблемы налогового администрирования / А. И. Пономарев, С. В. Никулина, К. К. Гойгереев. Ростов н/Д: МиниТайп, 2011. - С. 5.
}

данных, взятых из жизни, не наименьшим из которых является истинная оценка поведения налогоплательщиков при предоставлении отчетности о доходах. В условиях реальной жизни трудно измерить и измерить точно то, что люди по своей природе хотят скрыть. Уместен здесь потенциальный компромисс между попыткой принуждения и оказанием информационной помощи. Измерение и идентификация отдельных результатов эксперимента с реальными данными - задачи трудные; тем не менее мы в состоянии сделать это, вводя принуждение и помощь по отдельности. Необходимо принять во внимание неоднородность индивидуальных мотиваций среди налогоплательщиков, когда речь идет о соблюдении налоговой дисциплины, а также возможные дифференциальные результаты деятельности налоговых органов, которые могут скорее передвинуть некоторых лиц из одного класса поведения (к примеру, не выполняющий требования) в другой (выполняющий требования), нежели сделать всех лиц более законопослушными.

На самом базовом уровне решение в пользу выполнения налоговых требований может быть представлено в виде теории экономических преступлений. Здесь налогоплательщик воспринимается как азартный игрок меж двух состояний: в одном состоянии налогоплательщик предоставляет информацию о доходах (и уплачивает налоги), а в другом состоянии налогоплательщик не представляет информацию о доходах (и таким образом уклоняется от уплаты налогов). Налогоплательщик сравнивает предполагаемую выгоду от представления информации о доходах и предполагаемую пользу от уклонения от уплаты налогов.

Более точно, предположим, что налогоплательщик получает доход $I$ и должен решить какую часть дохода заявить налоговым органам. Заявленный доход $R$ облагается налогом по ставке $t$. Незаявленный доход не облагается налогом; однако налогоплательщик может 


\section{Налоги и налогообложение - №1(103) • 2013}

быть подвергнут проверке с фиксированной и известной вероятностью $p$. В этом случае весь незаявленный доход выявляется и штраф $f$ накладывается на каждый неуплаченный налог. Доход налогоплательщика Ic, если его выявят на сокрытии дохода составит

$$
\mathrm{Ic}=\mathrm{I}-\mathrm{tR}-\mathrm{ft}(\mathrm{I}-\mathrm{R}),(1)
$$

в то время, как доход IN налогоплательщика в случае не выявления укрытия дохода составит

$$
\mathrm{I}_{N}=\mathrm{I}-\mathrm{tR} \text {. (2) }
$$

Налогоплательщик выбирает такое значение $R$ (заявленный доход), чтобы получить максимальную выгоду EU(I) от уклонения уплаты налогов, или

$$
\mathrm{EU}(\mathrm{I})=\mathrm{pU}(\mathrm{IC})+(1-\mathrm{p}) \mathrm{U}(\mathrm{IN}),(3)
$$

где предполагается, что выгода $U(I)$ является функцией только дохода и где $E$ является параметром ожидания. Эта оптимизация порождает обычные условия первого и второго порядка, которые могут быть рассмотрены, чтобы проверить ответную реакцию налогоплательщика на изменения в различных параметрах. В случае где $R$ (заявленный доход) $<I$ (доход реальный), будет слишком прямолинейно показать, что возрастающая вероятность проверки и/или штраф приведут к большему выполнению налоговых требований.

Такой подход является, конечно, чрезмерным упрощением широко распространенного действия, которую мы называем «уклонением от уплаты налогов». Действительная реальность, в которой налогоплательщики принимают решения, гораздо более сложная, и эти сложности сказываются на поведении таким путем, что все это выходит далеко за рамки стандартной модели.

Еще одним упрощением является то, что этот подход исследует только решение о сообщении сведений о доходах. Этому также предшествует решение о подаче налоговой декларации, когда решается вопрос, подавать ли вообще эту декларацию. Учитывая, что неподающие декларацию и вовсе остаются «вне системы» и таким образом рискуют быть отобранными для налоговой проверки, традиционная политика ответа усилением принудительных мер не эффективна. Традиционный анализ решения о сообщении сведений о доходах не в полной мере отражает решение налогоплательщика о подаче декларации, потому что подача налоговой декларации, где налоговые обязательства указаны не в полном объеме, в корне отличается от ситуации, когда декларация о доходах и вовсе не подается. Уклонение в процессе подачи декларации и сообщения сведений о доходах повышает вероятность проверки, поскольку налоговая декларация находится «в системе»; декларация, которая не была подана, может привести к проверке в гораздо меньшей степени. Однако, если налогоплательщик, который не подал декларацию, будет уличен в этом, на него могут накладываться дополнительные штрафные санкции. Существуют также временные и ресурсные траты на подачу декларации. Реальная альтернатива, с которой сталкивается налогоплательщик, это низкая вероятность выявления неподачи декларации (плюс нулевые траты времени и ресурсов) против высоких штрафов за выявленную неподачу. Для принятия какого-либо решения по налоговой декларации налогоплательщик должен сравнить ожидаемую пользу от подачи с ожидаемой пользой от неподачи, при этом налогоплательщик, который подает декларацию, должен затем определить какой доход он укажет в декларации.

Другим важным упрощением в стандартной теории является то, что она по умолчанию предполагает, что налогоплательщик знает наверняка реальный размер налогового обязательства. На самом деле расчет налогового обязательства налогоплательщика - дело непростое. Налоговый кодекс безжалостен в своей сложности, и расчет допустимых выче- 
тов, кредитов и тому подобное часто является предметов споров. Часто недекларированность доходов, которое можно интерпретировать как уклонение, является всего лишь непониманием правил со стороны плательщика. В таких случаях решения налоговых органов могут оказаться пристрастными, и налогоплательщик реагирует на подобные решения снижением первоначального уровня соблюдения налоговой дисциплины и ожиданием проверки, чтобы получить подлинную интерпретацию. Таким образом, сложность в налоговом режиме может обернуться более низким уровнем соблюдения налоговой дисциплины, т.к. налогоплательщик скорее склонен рисковать, и высока вероятность ответа на подобные сложности преднамеренным уклонением от уплаты налогов.

Таким образом, сложность придает «расплывчатость» различным элементам, которые влияют на принятие решения налогоплательщиком о предоставлении сведений о доходах. Налогоплательщики, нейтральные к риску, будут просто основывать свои сведения о доходах на средних показателях. Однако лица, не расположенные к риску, могут предвидеть возможность переплаты в случае неопределенности и ответят на это большим уклонением от уплаты налогов. Предположим, что этот самый налогоплательщик информирован посредством проверки, что неопределенность привела к значительному штрафу. Этот человек может в будущем ответить еще большим уклонением, полагая, что двусмысленность в налоговом обязательстве - это вина налогового органа и что уклонение оправдано. Это предполагает, что выполнение налогового законодательства может быть усилено при оказании налоговыми органами всесторонней помощи налогоплательщикам. В особенности, когда услуги, оказанные налоговым органом, воспринимаются как полезные и ответы на вопросы даны своевременно и точно. В этом случае налоговая дисциплина вероятнее всего выше, чем когда взаимодействие принимает характер противоречий.

Существует, конечно, и другие соображения, которые могут повлиять на расчет налогоплательщика. Социальные психологи изучают влияние индивидуального восприятия прозрачности и честности налогового администрирования на соблюдение налоговой дисциплины.

Вместе взятые, эти факторы заставляют нас изменить стандартную модель уклонения. Предположим, что лицо, которое подает налоговую декларацию, сталкивается с временными и финансовыми затратами $C$ на заполнение декларации, а неденежная (или психическая) стоимость, связанная с уклонением от собственного налогового обязательства, если при этом лицо не подается, выражено через переменную $y$. Заметим, что психическая стоимость, связанная с обманом, появляется только, если действительно имеет место обман. Таким образом, плательщик, который полностью выполняет налоговые требования и не подвергается налоговой проверке, не испытывает изменения в полезности от психической стоимости уклонения.

Предположим, что подающий декларацию может вычесть некоторое количество D из заявленного дохода $R$ до уплаты налогов; альтернативно предположим, что налогоплательщик имеет право на налоговый вычет по налогам. Фактический уровень разрешенных вычетов до конца неясен (учитывая сложности Налогового кодекса) и ограничен (учитывая разные налоговые ведомства) и таким образом налоговые обязательства не могут быть сведены к нулю. Далее предположим, что лицо, которое не подает декларацию, избегает затрат по подаче С и неденежную стоимость $y$, тем не менее $p$ - это вероятность (возможно равная нулю), что лицо, которое не подало декларацию, выявлено контролем, в случае которого 


\section{Налоги и налогообложение - №1(103) • 2013}

налогоплательщики вынуждены оплатить все неоплаченные налоги по ставке $t$ плюс штраф (более высокий) по шкале $f$ на все неоплаченные налоги, где $f^{\prime}>f$.

Предположим, что налоговый орган может оказать «услуги». Чем выше сервисный уровень налогового органа, тем ниже неопределенность, связанная с допустимыми вычетами и тем ниже стоимость $C$ заполнения налоговой декларации. Также, чем выше уровень сервиса, тем выше размер «психической стоимости» $y$ и ниже польза от обмана.

Лицо, решившее не подавать декларацию (и кто таким образом не заявляет свой доход) имеет ожидаемую пользу, равную

$$
\mathrm{EU}(\mathrm{I})=\left(1-\mathrm{p}^{\prime}\right) \mathrm{U}(\mathrm{I})+\mathrm{p}^{\prime} \mathrm{U}\left(\mathrm{I}-\left(1+f^{\prime}\right) t \mathrm{I}\right) \text {. (4) }
$$

Лицо, которое решает подать декларацию и заявить свой доход имеет доход, определенный модифицированными версиями дохода в двух состояниях. C налоговым вычетом доход IC теперь становится

$$
\begin{aligned}
& \mathrm{Ic}=\mathrm{I}-\mathrm{t}(\mathrm{R}-\mathrm{D})-f \mathrm{tp}(\mathrm{I}-(\mathrm{R}-\mathrm{D}))-\mathrm{C},(5) \\
& \text { а доход IN в уравнении (2) становится } \\
& \mathrm{IN}=\mathrm{I}-\mathrm{t}(\mathrm{R}-\mathrm{D})-\mathrm{C}-y .(6)
\end{aligned}
$$

Определение ожидаемой пользы от подачи декларации (уравнение 3) не меняется и повторяется здесь как уравнение 7 или

\section{$\mathrm{EU}(\mathrm{I})=\mathrm{pU}(\mathrm{IC})+(1-\mathrm{p}) \mathrm{U}(\mathrm{IN}) .(7)$}

Налогоплательщик теперь имеет дело с более сложным расчетом. В первую очередь он должен решить, подавать или нет декларацию, сравнивая показатель ожидаемой пользы от неподачи из уравнения 4 с ожидаемой пользой от подачи и заявления оптимального количества дохода и вычетов в уравнении 7, используя модифицированные определения $I C$ и $I N$ в уравнениях 5 и 6 соответственно. Если лицо решит подать декларацию, он должен затем выбрать оптимальный размер заявленного дохода и вычетов, исходя из максимума в уравнениях 5-7.

В виду многообразия составляющих было бы слишком упрощенно показать в рамках этого примера, что оказание разъ- яснительных услуг налоговых органов улучшают выполнение налоговых требований путем снижения неясности вокруг вычетов, а также перехода к более «дружественному» взаимодействию между налоговым органом и налогоплательщиком.

Таким образом, наш результат показывает, что налогоплательщики сообщают меньше сведений о доходах, когда их обязательство неопределенно, но этот низкий уровень декларирования более чем уравновешивается, когда налоговый орган обеспечивает доступной информацией налогоплательщиков. Это предполагает, что действия налоговых органов по повышению услуг для налогоплательщиков могут быть важным инструментом по борьбе с уклонением от уплаты налогов. Точно также мы полагаем, что налоговая неопределенность снижает подачу деклараций, но предоставление информации налоговыми органами и здесь устраняет эффект неопределенности на подачу декларации.

В соответствии с п. 4. ст. 32 Налогового кодекса Российской Федерации налоговые органы обязаны проводить разъяснительную работу по применению законодательства о налогах и сборах, а также принятых в соответствии с ним нормативных правовых актов, разъяснять порядок заполнения форм установленной отчетности, давать разъяснения о порядке исчисления и уплаты налогов и сборов. Налогоплательщики в соответствии с п. 1 ст. 21 Налогового кодекса Российской Федерации вправе получать по месту своего учета от налоговых органов бесплатную информацию о действующих налогах и сборах, законодательстве о налогах и сборах и принятых в соответствии с ним нормативных правовых актах, порядке исчисления и уплаты налогов и сборов, правах и обязанностях налогоплательщиков, полномочиях налоговых органов и их 
должностных лиц, а также получать формы налоговых деклараций (расчетов) и разъяснения о порядке их заполнения.

Однако если судить по результатам, то по многим направлениям, по которым в других развитых странах достигнуты заметные успехи, у нас в стране вся работа, можно сказать, еще в самом начале. ${ }^{2}$ Так, ранее, в целях расширения деятельности по налоговому консультированию на территории Российской Федерации, в порядке эксперимента, были созданы консультационные пункты при управлениях МНС России по Саратовской, Калужской, Кировской, Свердловской, Московской областям, Красноярскому краю и г. Москве. Взаимодействие консультационных центров и налоговых органов строилось на основе отношений учредительства. В учредительных документах регламентировались вопросы взаимодействия консультационного центра и учредившего его налогового органа, а также вопросы контроля деятельности центра. Методическое и методологическое обеспечение работы по организации оказания консультационной помощи налогоплательщикам было возложено на отдел по научно-методической и консультационной работе МНС России при участии федерального государственного учреждения «Центральная консультационная служба МНС России»»». В настоящее время Федеральная налоговая служба отказалась от данного эксперимента, признав нецелесообразность осуществления налогового консультирования налогообязанных лиц в рамках исполнения государственной функции, взяв на себя реализацию задач по информированию налогоплательщиков и разъяснительную работу. ${ }^{3}$

\footnotetext{
${ }^{2}$ Пайзулаев И.Р. Проблемы соблюдения налоговой дисциплины и методы борьбы с уклонением от налогов. // Налоги и налогообложение. - 2012. - №4. - С. 18.

${ }^{3}$ Надточий Е.В. Взаимодействие субъектов налоговых отношений в ходе выполнения обязанностей и реализации прав налогоплательщиками. // Налоги и налогообложение. - 2012. - №5. - С. 15-16.
}

На наш взгляд в целях совершенствования налогового администрирования и повышения соблюдения налоговой дисциплины налогоплательщиками должна быть продолжена работа по расширению информационных услуг и разъяснительных работ налогоплательщикам.

Таким образом, стратегии по улучшению выполнения налоговых требований должны основываться не только на принуждении. Взамен требуется многогранная политика, которая усиливает принуждение, но также необходимо, чтобы она усиливала другие административные средства, такие как информационные услуги. Иными словами, выявление и наказание должны присутствовать, но требуются и иные инструменты. Должен быть широкий спектр воздействия, который отразил бы такой же широкий спектр мотиваций, лежащих в основе решений налогоплательщика по налоговым обязательствам.

\section{Библиография:}

1. Налоговый кодекс Российской Федерации, части первая и вторая // СПС «КонсультантПлюс», 2012.

2. Актуальные проблемы налогового администрирования / А. И. Пономарев, С. В. Никулина, К. К. Гойгереев. Ростов н/Д: МиниТайп, 2011.

3. Надточий Е.В. Взаимодействие субъектов налоговых отношений в ходе выполнения обязанностей и реализации прав налогоплательщиками. // Налоги и налогообложение. - 2012. - №5.

4. Пайзулаев И.Р. Проблемы соблюдения налоговой дисциплины и методы борьбы с уклонением от налогов. // Налоги и налогообложение. - 2012. - №4. 


\section{Налоги и налогообложение - №1(103) • 2013}

\section{References (transliteration):}

1. Aktual'nye problemy nalogovogo administrirovaniya / A. I. Ponomarev, S. V. Nikulina, K. K. Goygereev. - Rostov n/D: MiniTayp, 2011.

2. Nadtochiy E.V. Vzaimodeystvie sub'ektov nalogovykh otnosheniy $\mathrm{v}$ khode vypol- neniya obyazannostey i realizatsii prav nalogoplatel'shchikami. // Nalogi i nalogooblozhenie. - 2012. - №5.

3. Payzulaev I.R. Problemy soblyudeniya nalogovoy distsipliny i metody bor'by s ukloneniem ot nalogov. // Nalogi i nalogooblozhenie. 2012. - №4. 